\title{
Aromatic Poly(ether imide)s Bearing Isopropylidene or Hexafluoroisopropylidene Links in the Main Chain
}

\author{
Sheng-Huei HsiaO ${ }^{\dagger}$ and Chou-Huan Yu \\ Department of Chemical Engineering, Tatung Institute of Technology, \\ 40 Chungshan North Rd., Sec. 3, Taipei 104, Taiwan, \\ Republic of China
}

(Received July 3, 1997)

\begin{abstract}
Two bis(ether anhydride) monomers, 2,2-bis[4-(3,4-dicarboxyphenoxy)phenyl]propane dianhydride (4) and 2,2-bis[4-(3,4-dicarboxyphenoxy)phenyl]hexafluoropropane dianhydride (4-F), were synthesized from readily available compounds in three steps in high yields. Two series of poly(ether imide)s $\mathbf{7}_{\mathrm{a}-\mathrm{g}}$ and $\mathbf{7}_{\mathrm{a}-\mathrm{g}}-\mathbf{F}$ based on dianhydrides $\mathbf{4}$ and $\mathbf{4 - F}$, respectively, were synthesized by a conventional two-step procedure that included a ring-opening polyaddition to give poly(amic acid)s, followed by cyclodehydration to polyimides. The intermediate poly(ether amic acid)s and the poly(ether imide)s had inherent viscosities in the range of $0.29-1.09 \mathrm{dLg}^{-1}$ and $0.21-0.98 \mathrm{dLg}^{-1}$, respectively. Except for the poly(ether imide)s derived from benzidine, the others afforded flexible and tough films. Most of the obtained poly(ether imide)s are organic-soluble. The glass transition temperatures $\left(T_{\mathrm{g}}\right)$ of these polymers ranged from 204 to $259^{\circ} \mathrm{C}$. Degradation temperatures for $10 \%$ weight loss all occurred above $505^{\circ} \mathrm{C}$ in nitrogen and above $501^{\circ} \mathrm{C}$ in air. Fluorine-containing poly(ether imide)s showed higher solubility, $T_{\mathrm{g}} \mathrm{s}$ and degradation temperatures in nitrogen, as compared to their respective nonfluorine-containing counterparts. KEY WORDS Poly(ether imide)s / Fluorinated Polyimides / Isopropylidene / Hexafluoroisopropylidene /
\end{abstract}

Aromatic polyimides are well known as high-performance polymer materials for their excellent mechanical and electrical properties, high thermal and thermooxidative stability, and outstanding solvent resistance. ${ }^{1,2}$ A large number of polyimides with unique properties have been introduced for various industrial applications since their commercialization in the beginning of the 1960 's. However, aromatic polyimides have one major disadvantage of typically being insoluble and intractable after conversion from the poly(amic acid) to the polyimide form. Most conventional processing techniques involve the fabrication of poly(amic acid) precursors followed by thermal or chemical imidization. Problems can arise because the poly(amic acid)s are thermally and hydrolytically unstable. The water evolved from imidization can also form voids in bulk materials.

Thus, many attempts have been made to improve the processing properties of aromatic polyimides, particularly their solubility and fusibility, by incorporating ether or other flexibilizing linkages into the main chain. ${ }^{3-8}$ Considerable attention has been devoted lately to the synthesis of fluorine-containing polyimides, particularly to those with hexafluoroisopropylidene $(6 \mathrm{~F})$ groups. $^{9-15}$ Frequently, the incorporation of $6 \mathrm{~F}$ groups into a polymer backbone will improve the solubility and other properties such as flame retardance, thermal stability, oxidative resistance, and environmental stability, while there is often a decrease in color, crystallinity, dielectric constant, and moisture absorption.

In the present study, the synthesis and characterization of fluorine and nonfluorine-containing poly(ether imide)s are reported giving particular attention to their solubility and thermal properties. The differences in physical properties upon fluorination are investigated by using 2,2-bis[4-(3,4-dicarboxyphenoxy)phenyl]hexafluoropropane dianhydride (4-F as shown in Scheme 1) and the corresonding nonfluorine-containing monomer.

\footnotetext{
${ }^{\dagger}$ To whom all correspondence should be addressed.
}

\section{EXPERIMENTAL}

\section{Materials}

The reagents employed in the syntheses of bis(ether anhydride)s 4 and 4-F including 2,2-bis(4-hydroxyphenyl)propane (bisphenol A) (1) (TCI), 2,2-bis(4-hydroxyphenyl)hexafluoropropane (bisphenol AF) (1-F) (Chris$\mathrm{kev}$ ), toluene (Alps), potassium carbonate $\left(\mathrm{K}_{2} \mathrm{CO}_{3}\right.$; Fluka), $N, N$-dimethylformamide (DMF; Fluka), potassium hydroxide (Wako), and acetic anhydride (Janssen) were used without previous purification. $p$-Phenylenediamine $\left(\mathbf{5}_{\mathrm{a}}\right.$ ) (Wako) was purified by sublimation. $m$-Phenylenediamine $\left(\mathbf{5}_{\mathrm{b}}\right)$ (Janssen) was vacuum-distilled prior to use. Benzidine $\left(\mathbf{5}_{\mathrm{c}}\right)$ (TCI) was recrystallized from the mixture of ethanol and benzene. 4,4'-Bis(4-aminophenoxy)biphenyl $\left(\mathbf{5}_{\mathrm{g}}\right)\left(\mathrm{mp} 198-199^{\circ} \mathrm{C}\right)$ was prepared by a reported method ${ }^{16}$ that involved the nucleophilic substitution reaction of $4,4^{\prime}$-biphenol with $p$-chloronitrobenzene in the presence of potassium carbonate and subsequent reduction of the intermediate dinitro compound using hydrazine as the reducing agent and palladium as the catalyst. The other diamines such as 4,4'-diaminodiphenylmethane $\left(5_{\mathrm{d}}\right)$ (TCI), 4,4'-diaminodiphenyl ether $\left(\mathbf{5}_{\mathrm{e}}\right)$ (TCI), and 1,4-bis(4-aminophenoxy)benzene $\left(5_{\mathrm{f}}\right)$ (TCI) were used as received. $N, N$-Dimethylacetamide (DMAc) was purified by distillation under reduced pressure over calcium hydride and stored in the presence of $4 \AA$ molecular sieves.

\section{Monomer Synthesis}

2,2-Bis[4-(3,4-dicyanophenoxy)phenyl]hexafluoropropane (2-F). In a $300-\mathrm{mL}$ flask, $25 \mathrm{~g}(0.074 \mathrm{~mol})$ of bisphenol AF (1-F) and $20.55 \mathrm{~g}(0.148 \mathrm{~mol})$ of $\mathrm{K}_{2} \mathrm{CO}_{3}$ were suspended in a mixture of $200 \mathrm{~mL}$ of DMF and $70 \mathrm{~mL}$ of toluene. The suspension solution was heated at a reflux temperature using a Dean-Stark trap to remove the water azeotropically. After complete removal of water, the residual toluene was distilled off. Then, the reaction mixture was cooled to about $60^{\circ} \mathrm{C}$, and $26.5 \mathrm{~g}$ 
$(0.15 \mathrm{~mol})$ of 4 -nitrophthalonitrile was added and heating was continued at $60^{\circ} \mathrm{C}$ for $24 \mathrm{~h}$. After cooling, the reaction mixture was poured into $700 \mathrm{~mL}$ of water, and the precipitated light yellow solid was collected and washed thoroughly with methanol and water. The yield of the crude product was quantitative. The crude product was purified by recrystallization from acetonitrile. The yield of the purified product was $31 \mathrm{~g}(71 \%)$; mp $230^{\circ} \mathrm{C}$. The IR spectrum $(\mathrm{KBr})$ exhibited absorptions at 2238 (C $\equiv \mathrm{N}$ str.), $1591-1487$ (arom. $\mathrm{C}=\mathrm{C}$ str.), 1249 (C-O$\mathrm{C}$ str.) and $1210 \mathrm{~cm}^{-1}(\mathrm{C}-\mathrm{F}$ str. $)$.

Anal. Calcd for $\mathrm{C}_{31} \mathrm{H}_{14} \mathrm{~N}_{4} \mathrm{O}_{2} \mathrm{~F}_{6}$ (588.47): C, 63.27\%; H, 2.40\%; N, 9.52\%. Found: C, 62.90\%; H, 2.52\%; N, $9.44 \%$

2,2-Bis[4-(3,4-dicyanophenoxy)phenyl]propane (2) was synthesized starting from bisphenol A (1) and 4nitrophthalonitrile in an analogous procedure. Yield (after recrystallization): $28.57 \mathrm{~g}(67 \%) ; \mathrm{mp} 185-187^{\circ} \mathrm{C}$.

IR (KBr): 2232 (C $\equiv \mathrm{N}$ str.), $1591-1486$ (arom. $\mathrm{C}=\mathrm{C}$ str.) and $1252 \mathrm{~cm}^{-1}(\mathrm{C}-\mathrm{O}-\mathrm{C}$ str. $)$.

Anal. Calcd for $\mathrm{C}_{31} \mathrm{H}_{20} \mathrm{~N}_{4} \mathrm{O}_{2}$ (483.55): C, 74.52\%; $\mathrm{H}$, $4.17 \%$; N, $11.59 \%$. Found: C, $74.47 \% ; H, 4.35 \%$; N, $11.65 \%$

2,2-Bis[4-(3,4-dicarboxyphenoxy)phenyl]hexafluoropropane $(3-\mathrm{F})$. In a $1000-\mathrm{mL}$ flask, a suspension of bis(ether dinitrile) $2-\mathbf{F}(30 \mathrm{~g} ; 0.051 \mathrm{~mol})$ in an ethanolwater mixture $(200: 200 \mathrm{~mL})$ containing dissolved $57.2 \mathrm{~g}$ $(1.02 \mathrm{~mol})$ of $\mathrm{KOH}$ was boiled under reflux. The suspension turned into a clear solution after about $2 \mathrm{~h}$. Reflux was continued for about $24 \mathrm{~h}$ until the evolution of ammonia had ceased. The resulting hot, clear solution was filtered to remove any insoluble impurities. The hot filtrate was allowed to cool and acidified by conc $\mathrm{HCl}$ to $\mathrm{pH}=1-2$ while stirred. The product phased out in the bottom of the beaker as a viscous lump, which was washed repeatedly with water and dried. The resulting bis(ether acid) 3-F was not purified and not characterized in detail but was used directly in the synthesis of bis(ether anhydride) 4-F

IR (KBr): $2400-3600$ (O-H str.), 1717 (C=O str.), $1244 \mathrm{~cm}^{-1}$ (C-O-C str.).

2,2-Bis[4-(3,4-dicarboxyphenoxy)phenyl]propane (3) was prepared from the alkaline hydrolysis of corresponding bis(ether dinitrile) $\mathbf{2}$ in a similar procedure. The bis(ether diacid) 3 was not characterized and were used directly in the synthesis of bis(ether anhydride) 4 .

2,2-Bis[4-(3,4-dicarboxyphenoxy)phenyl]hexafluoropropane dianhydride (4-F). In a $1000-\mathrm{mL}$ flask, bis(ether diacid) 3-F was suspended in $300 \mathrm{~mL}$ of acetic anhydride. The suspension was boiled under reflux until turning into a clear solution. The resulting hot, clear solution was filtered to remove any insoluble impurities. On cooling, the bis(ether anhydride) started to crystallize and next day the product was filtered off, washed with dry toluene, and dried in vacuo, to give $16.9 \mathrm{~g}$ yield. The filtrate was concentrated to about $1 / 3$ its original volume, and another $12.5 \mathrm{~g}$ of the product was collected. Thus, a total yield was about $92 \%$ theoretically. The mp of $\mathbf{4 - F}$ was $228^{\circ} \mathrm{C}$.

IR (KBr): 1854 (asym. $\mathrm{C}=\mathrm{O}$ str.), 1783 (sym. $\mathrm{C}=\mathrm{O}$ str.), 1595-1483 (arom. C = C str.), 1288 (C-O-C str.), and $1207 \mathrm{~cm}^{-1}$ (C-F str.).

Anal. Calcd for $\mathrm{C}_{31} \mathrm{H}_{14} \mathrm{O}_{8} \mathrm{~F}_{6}$ (628.44); C, 59.25\%; H,
$2.25 \%$. Found: C, $58.02 \%$; H, $2.29 \%$

2,2-Bis[4-(3,4-dicarboxyphenoxy)phenyl]propane dianhydride (4) was prepared from the dehydration of corresponding bis(ether diacid) 3 in a similar method. Yield, $20.06 \mathrm{~g}(66 \%)$; mp $182-184^{\circ} \mathrm{C}$.

IR (KBr): 1849 (asym. $\mathrm{C}=\mathrm{O}$ str.), 1781 (sym. $\mathrm{C}=\mathrm{O}$ str.), 1619-1479 (arom. $\mathrm{C}=\mathrm{C}$ str.), and $1285 \mathrm{~cm}^{-1}(\mathrm{C}-$ $\mathrm{O}-\mathrm{C}$ str.).

Anal. Calcd for $\mathrm{C}_{31} \mathrm{H}_{20} \mathrm{O}_{8}(520.49)$ : C, 71.54\%; $\mathrm{H}$, $3.87 \%$. Found: C, $70.37 \%$; H, 3.79\%.

\section{Synthesis of Poly(ether imide)s}

A typical polymerization procedure is as follows. $4,4^{\prime}$ Diaminophenyl ether $\left(\mathbf{5}_{\mathrm{e}}\right)(0.2417 \mathrm{~g} ; 1.21 \mathrm{mmol})$ was dissolved in $9.5 \mathrm{~mL}$ of dried DMAc in a $50-\mathrm{mL}$ flask. After the diamine was dissolved completely, $0.7583 \mathrm{~g}$ (1.21 $\mathrm{mmol}$ ) of bis(ether anhydride) 4-F was added in one portion. The mixture was stirred at room temperature for $3 \mathrm{~h}$. The inherent viscosity of the resulting poly(ether amic acid) $\left(6_{\mathrm{e}}-\mathbf{F}\right)$ was $0.50 \mathrm{dL} \mathrm{g}^{-1}$, as measured in DMAc at a concentration of $0.5 \mathrm{~g} \mathrm{dL}^{-1}$ at $30^{\circ} \mathrm{C}$. The polymer solution was poured into a $9-\mathrm{cm}$ glass culture dish, which was placed in a $90^{\circ} \mathrm{C}$ oven overnight to remove the solvent. The semi-dried poly(ether amic acid) film was further dried and transformed into poly(ether imide) by sequential heating at $150^{\circ} \mathrm{C}$ for $20 \mathrm{~min}, 180^{\circ} \mathrm{C}$ for $20 \mathrm{~min}$, $220^{\circ} \mathrm{C}$ for $20 \mathrm{~min}$, and $250^{\circ} \mathrm{C}$ for $30 \mathrm{~min}$. By soaking in hot water, a flexible poly(ether imide) film of $7 \mathrm{a}-\mathrm{F}$ selfstripped off from the glass surface.

All other poly(ether imide)s were prepared by an analogous procedure.

\section{Measurements}

IR spectra were recorded on a Jasco FT/IR-7000 Fourier transform infrared spectrometer. Elemental analyses were run in a Perkin-Elmer Model $2400 \mathrm{C}, \mathrm{H}$, $\mathrm{N}$ analyzer at the National Taiwan University (Taipei). The inherent viscosities were measured with an Ubbelohde viscometer thermostated at $30^{\circ} \mathrm{C}$. A Sinku Riko DSC7000 thermal differential scanning calorimeter equipped with a Sinku Riko TA-7000 analyzer was used to determine the thermal transitions. Heating rate was $20^{\circ} \mathrm{C}$ $\min ^{-1}$. Glass transition temperatures $\left(T_{\mathrm{g}} \mathrm{s}\right)$ were read at the middle of the change in the heat capacity, and were taken from the second heating scan after quick cooling. Thermogravimetry (TG) was conducted with a Rigaku thermoflex TG 8110 coupled to a Rigaku TAS-100 thermal analysis station. Experiments were carried out on $9-11 \mathrm{mg}$ samples heated in flowing nitrogen or air $\left(50 \mathrm{~cm}^{3} \mathrm{~min}^{-1}\right)$ at a heating rate of $20^{\circ} \mathrm{C} \mathrm{min}^{-1}$. Wideangle $\mathrm{X}$-ray diffraction measurements were performed at room temperature (about $25^{\circ} \mathrm{C}$ ) on a Siemens Kristalloflex D5000 X-ray diffractometer, using Ni-filtered $\mathrm{Cu}-K_{\alpha}$ radiation $(40 \mathrm{kV}, 15 \mathrm{~mA})$. The scanning rate was $2^{\circ}$ min $^{-1}$ over a range of $2 \theta=5-40^{\circ}$. An Instron universal tester Model HT-9102 (Hung Ta Instrument Co., Taiwan) with a load cell $100 \mathrm{~kg}$ was used to study the stress-strain behavior of the samples. A gauge of $2 \mathrm{~cm}$ and a crosshead speed of $5 \mathrm{~cm} \mathrm{~min}^{-1}$ were used for this study. Measurements were performed at room temperature with film specimens $(6 \mathrm{~cm}$ long, $0.5 \mathrm{~cm}$ wide, and about $0.1 \mathrm{~mm}$ thick). An average of at least five individual determinations was used. 

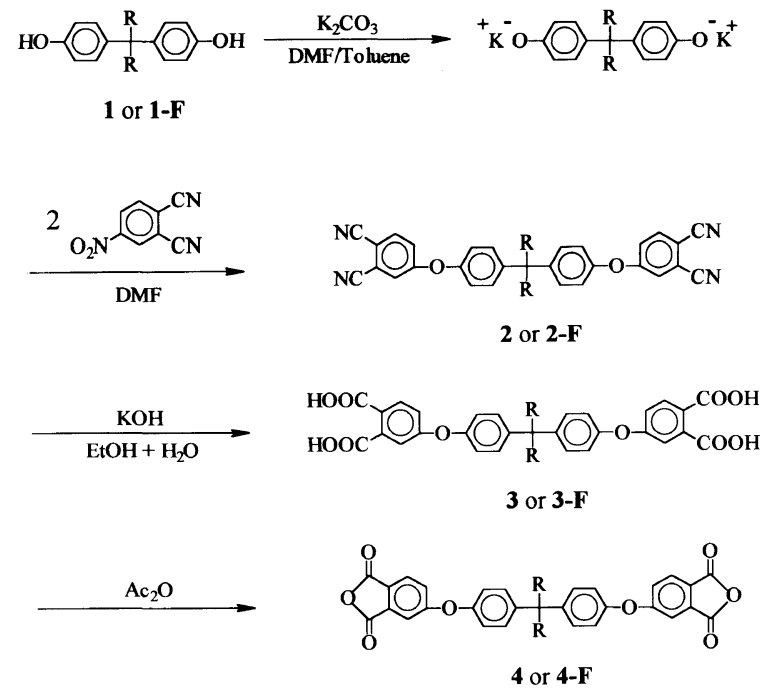

$1,2,3,4: \mathrm{R}=-\mathrm{CH}_{3}$

1-F, 2-F, 3-F, 4-F: $\mathrm{R}=-\mathrm{CF}_{3}$

Scheme 1. Preparation of bis(ether anhydride)s.

\section{RESULTS AND DISCUSSION}

\section{Monomer Synthesis}

According to a reported method, ${ }^{4}$ bis(ether anhydride)s $\mathbf{4}$ and 4-F were prepared using a three-stage route starting from the nitro displacement reaction of the dipotassium phenolates of diols 1 or 1-F with 4-nitrophthalonitrile (Scheme 1). The yields in each step were high, and the structure of bis(ether anhydride)s was confirmed by elemental analysis and infrared spectroscopy. The IR spectra of bis(ether dinitrile)s $\mathbf{2}$ and $\mathbf{2 - F}$ were characterized by a sharp absorption near $2240 \mathrm{~cm}^{-1}$ due to the cyano group. The most characteristic bands of bis(ether anhydride)s $\mathbf{4}$ and $\mathbf{4 - F}$ were observed near 1850 and $1780 \mathrm{~cm}^{-1}$, pointing at the asymmetrical and symmetrical stretching vibrations of the cyclic anhydride carbonyl groups.

\section{Synthesis of Poly(ether imide)s}

Poly(ether imide)s $7_{\mathrm{a}-\mathrm{g}}$ and $\mathbf{7}_{\mathrm{a}-\mathrm{g}}-\mathbf{F}$ were synthesized from bis(ether anhydride)s $\mathbf{4}$ and 4-F, respectively, with various aromatic diamines $\mathbf{5}_{\mathbf{a}-\mathrm{g}}$ by the conventional two-stage process, involving a ring-opening polyaddition and subsequent thermal cyclodehydration. The bis(ether anhydride)s were added to a solution of the diamines in DMAc at room temperature (Scheme 2). The solid content was maintained at $10 \mathrm{wt} \%$. High molecular weight poly(ether amic acid) solution with inherent viscosities of $0.29-1.09 \mathrm{dL} \mathrm{g}^{-1}$ were obtained in $3 \mathrm{~h}$. Transparent and flexible films of the poly(ether amic acid)s could be obtained by casting the resulting polymer DMAc solutions at $90^{\circ} \mathrm{C}$ for $24 \mathrm{~h}$. Even those polymers having the lower viscosities $\left(0.29 \mathrm{dL} \mathrm{g}^{-1}\right)$ gave quite flexible films, which can be explained by the presence of the isopropylidene or hexafluoroisopropylidene $(6 \mathrm{~F})$ units and other flexible groups, such as ether, in the main chain. The thermal conversion to poly(ether imide)s was carried out by heating the poly(ether amic acid) films at $150^{\circ} \mathrm{C}$ for $20 \mathrm{~min}, 180^{\circ} \mathrm{C}$ for $20 \mathrm{~min}, 220^{\circ} \mathrm{C}$ for $20 \mathrm{~min}$,

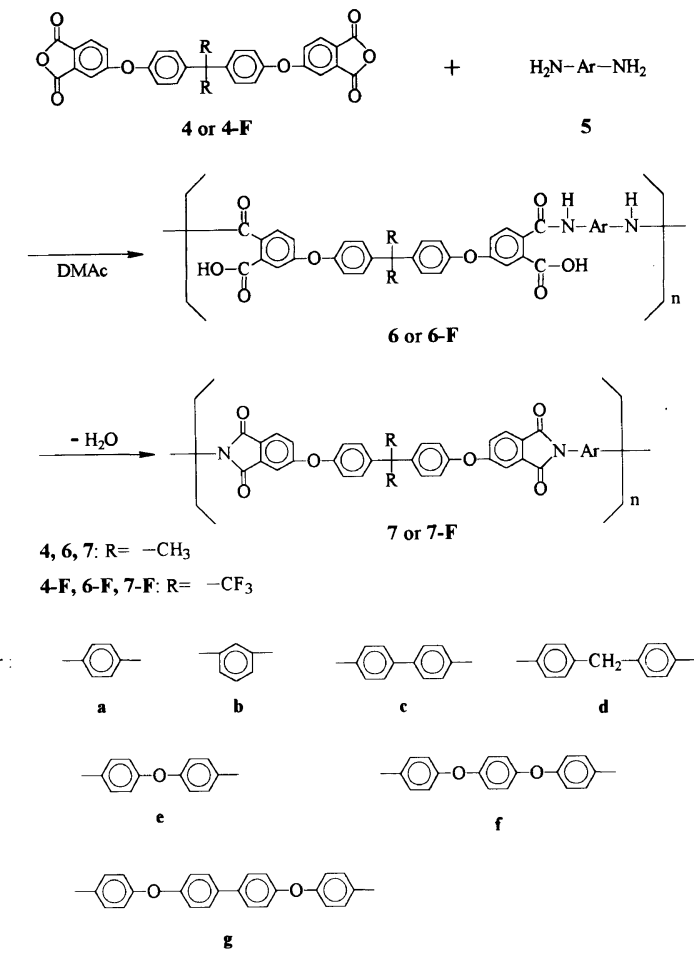

Scheme 2. Preparation of poly(ether imide)s.

and $250^{\circ} \mathrm{C}$ for $30 \mathrm{~min}$. Completion of the imidization by the heating program was confirmed by dynamic thermogravimetry of a sample of the poly(ether amic acid). It was found that the weight loss was complete around $230^{\circ} \mathrm{C}$, and the thermogravimetry curve of a sample showed no difference from the curve of a sample imidized as a film on a glass substrate. More rapid temperature elevation resulted in cracked or brittle films. The films of poly(ether imide)s $7_{\mathrm{c}}$ and $\mathbf{7}_{\mathrm{c}}-\mathbf{F}$ embrittled during thermal imidization, probably due to the presence of the rigid 4,4'-bis(phthalimido)biphenylene moiety in their macromolecular backbones. The other poly(ether imide) films were transparent, flexible, and tough. Poly(ether imide)s $7_{d-g}$ and $7_{e-f}-\mathbf{F}$ were readily soluble in polar solvents like DMAc, and $7_{a-d}-F$ were soluble in concentrated sulfuric acid. Therefore, the characterization of inherent viscosity was carried out without any difficulty, and the inherent viscosities of these poly(ether imide)s were in the range of $0.29-0.98 \mathrm{dL} \mathrm{g}^{-1}$. Poly(ether imide)s $7_{a-c}$ were insoluble in organic solvents, and they readily decomposed in concentrated sulfuric acid due to the presence of isopropylidene groups. Therefore, no attempts was made to characterize their inherent viscosities.

IR spectroscopy allows monitoring of the imide ring formation during curing. As the poly(ether amic acid) was converted into the poly(ether imide), the characteristic absorption bands of the imide ring were observed near 1780 (asym. $\mathrm{C}=\mathrm{O}$ str.), 1720 (sym. $\mathrm{C}=\mathrm{O}$ str.), 1390 (C-N str.), 1100 and $720 \mathrm{~cm}^{-1}$ (imide ring deformation), and those of amide and carboxyl groups in the regions of $2500-3500 \mathrm{~cm}^{-1}$ and $1500-1730 \mathrm{~cm}^{-1}$ disappeared.

\section{Properties of Poly(ether imide)s}

Solubility of poly(ether imide)s was studied qualitatively, and the results are listed in Table II. The solubilities 
Table I. The inherent viscosities and film quality of poly(ether amic acid)s and poly(ether imide)s

\begin{tabular}{|c|c|c|c|c|c|}
\hline \multicolumn{3}{|c|}{ Poly(ether amic acid) } & \multicolumn{3}{|c|}{ Poly(ether imide) } \\
\hline Code & $\begin{array}{c}\eta_{\mathrm{inh}}^{\mathrm{a}} \\
/ \mathrm{dL} \mathrm{g}^{-1}\end{array}$ & $\begin{array}{l}\text { Film }_{\text {quality }^{\mathrm{b}}}\end{array}$ & Code & $\begin{array}{c}\eta_{\mathrm{inh}} \\
/ \mathrm{dLg}^{-1}\end{array}$ & $\begin{array}{c}\text { Film } \\
\text { quality }^{\mathrm{e}}\end{array}$ \\
\hline $6_{a}$ & 0.51 & $\mathrm{~F}$ & $7 \mathrm{a}$ & $-^{\mathrm{c}}$ & $\mathrm{F}$ \\
\hline $6_{b}$ & 0.29 & $\mathrm{~F}$ & $7_{b}$ & $-^{c}$ & $\mathbf{F}$ \\
\hline $6_{c}$ & 0.79 & $\mathrm{~F}$ & $7_{\mathrm{c}}$ & $-^{c}$ & B \\
\hline $6_{d}$ & 0.36 & $\mathrm{~F}$ & $7_{d}$ & $0.60^{\mathrm{a}}$ & $\mathrm{F}$ \\
\hline $6_{e}$ & 0.73 & $\mathrm{~F}$ & $7 \mathrm{c}$ & $0.56^{\mathrm{a}}$ & $\mathrm{F}$ \\
\hline $6_{\mathrm{f}}$ & 0.84 & $\mathrm{~F}$ & $7_{f}$ & $0.87^{\mathrm{a}}$ & $\mathrm{F}$ \\
\hline $6 \mathrm{~g}$ & 1.09 & $\mathrm{~F}$ & $7_{\mathrm{g}}$ & $0.98^{\mathrm{a}}$ & $\mathrm{F}$ \\
\hline $6_{\mathrm{a}}^{\mathrm{g}}-\mathrm{F}$ & 0.29 & $\mathrm{~F}$ & $7_{\mathrm{a}}^{\mathrm{b}}-\mathrm{F}$ & $0.29^{\mathrm{d}}$ & $\mathrm{F}$ \\
\hline $6_{b}-F$ & 0.29 & $\mathrm{~F}$ & $7 \mathrm{~b}-\mathrm{F}$ & $0.28^{\mathrm{d}}$ & $\mathrm{F}$ \\
\hline $6_{c}-F$ & 0.42 & $\mathrm{~F}$ & $7_{c}-\mathrm{F}$ & $0.21^{\mathrm{d}}$ & B \\
\hline $6_{d}-F$ & 0.42 & $\mathrm{~F}$ & $7_{d}-F$ & $0.63^{d}$ & $\mathrm{~F}$ \\
\hline $6_{e}-F$ & 0.50 & $\mathrm{~F}$ & $7 \mathrm{e}_{\mathrm{e}}-\mathrm{F}$ & $0.68^{a}$ & $\mathrm{~F}$ \\
\hline $6_{\mathrm{f}}-\mathrm{F}$ & 0.36 & $\mathrm{~F}$ & $7_{\mathrm{f}}-\mathrm{F}$ & $0.72^{\mathrm{a}}$ & $\mathrm{F}$ \\
\hline $6_{g}-F$ & 0.45 & $\mathrm{~F}$ & $7 \mathrm{~g}-\mathrm{F}$ & $0.92^{\mathrm{a}}$ & $\mathrm{F}$ \\
\hline
\end{tabular}

${ }^{a}$ Measured in DMAc on $0.5 \mathrm{~g} \mathrm{dL}^{-1}$ at $30^{\circ} \mathrm{C}$. ${ }^{\mathrm{b}}$ Films were cast by slow evaporation of polymer solutios in DMAc. ${ }^{\mathrm{c}}$ Insoluble in DMAc and decomposed in $\mathrm{H}_{2} \mathrm{SO}_{4} \cdot{ }^{\mathrm{d}}$ Measured in concentrated $\mathrm{H}_{2} \mathrm{SO}_{4}$ on $0.5 \mathrm{~g} \mathrm{dL}^{-1}$ at $30^{\circ} \mathrm{C}$. ${ }^{\text {e }}$ Films were obtained by sequential heating of the poly(ether amic acid) films at $150^{\circ} \mathrm{C}$ for $20 \mathrm{~min}, 180^{\circ} \mathrm{C}$ for $20 \mathrm{~min}$, $220^{\circ} \mathrm{C}$ for $20 \mathrm{~min}$, and $250^{\circ} \mathrm{C}$ for $30 \mathrm{~min}$. B, brittle; F, flexible.

Table II. Solubility of poly(ether imide)s ${ }^{a}$

\begin{tabular}{ccccccc}
\hline \multirow{2}{*}{$\begin{array}{c}\text { Polymer } \\
\text { code }\end{array}$} & \multicolumn{5}{c}{ Solvent $^{\mathrm{b}}$} \\
\cline { 2 - 7 } & NMP & DMAc & DMF & DMSO & $m$-Cresol & THF \\
\hline $7_{\mathrm{a}}$ & - & - & - & - & - & - \\
$\mathbf{7}_{\mathrm{b}}$ & - & $\mathrm{S}$ & - & - & - & - \\
$\mathbf{7}_{\mathrm{c}}$ & - & - & - & - & - & - \\
$\mathbf{7}_{\mathrm{d}}$ & + & $+\mathrm{h}$ & - & - & + & - \\
$\mathbf{7}_{\mathrm{e}}$ & + & + & - & - & + & - \\
$\mathbf{7}_{\mathrm{f}}$ & + & $+\mathrm{h}$ & $\mathrm{S}$ & - & + & $\mathrm{S}$ \\
$\mathbf{7}_{\mathrm{g}}$ & + & + & $\mathrm{S}$ & - & + & $\mathrm{S}$ \\
$\mathbf{7}_{\mathrm{a}} \mathbf{- F}$ & $\mathrm{S}$ & - & $\mathrm{S}$ & $\mathrm{S}$ & $\mathrm{S}$ & $\mathrm{S}$ \\
$\mathbf{7}_{\mathrm{b}}-\mathbf{F}$ & $\mathrm{S}$ & $\mathrm{S}$ & $\mathrm{S}$ & $\mathrm{S}$ & $\mathrm{S}$ & $\mathrm{S}$ \\
$\mathbf{7}_{\mathrm{c}} \mathbf{- F}$ & $+\mathrm{h}$ & - & - & - & $+\mathrm{h}$ & - \\
$\mathbf{7}_{\mathrm{d}}-\mathbf{F}$ & + & $+\mathrm{h}$ & + & $+\mathrm{h}$ & $+\mathrm{h}$ & + \\
$\mathbf{7}_{\mathrm{e}} \mathbf{- F}$ & + & + & + & - & $+\mathrm{h}$ & + \\
$\mathbf{7}_{\mathrm{f}}-\mathbf{F}$ & + & + & + & $+\mathrm{h}$ & $+\mathrm{h}$ & + \\
$\mathbf{7}_{\mathrm{g}}-\mathbf{F}$ & + & + & + & - & - & + \\
\hline
\end{tabular}

${ }^{a}+$, soluble at room temperature; $+\mathrm{h}$, soluble on heating; $\mathrm{S}$, swelling; - , insoluble even on heating. ${ }^{\mathbf{b}} \mathrm{NMP}, N$-methyl-2-pyrrolidone; DMAc, $N, N$-dimethylacetamide; DMF, $N, N$-dimethylformamide; DMSO, dimethyl sulfoxide; THF, tetrahydrofuran.

of these polymers are partially dependent on the diamine components. Those derived from rigid diamines like $p$ phenylenediamine and benzidine, such as polymers $7_{\mathrm{a}}$, $\mathbf{7}_{\mathrm{c}}, \mathbf{7}_{\mathrm{a}} \mathbf{- F}$, and $\mathbf{7}_{\mathrm{c}}-\mathbf{F}$, were almost all insoluble in all the solvents tested. This can be attributable to the existence of the rigid planar 1,4-bis(phthalimido)phenylene or 4,4'-bis(phthalimido)biphenylene units in their polymer backbones, which may lead to a higher packing density of polymer chains. The poly(ether imide)s $7_{\mathrm{b}}$ and $7_{\mathrm{b}}-\mathrm{F}$ based on $m$-phenylenediamine also revealed poor solubility. However, introduction of flexible kinks in the diamine components led to an enhanced solubility. Almost all the polymers derived from flexible diamines were soluble in polar solvents such as NMP, DMAc, and $m$-cresol. As compared to the nonfluorine-containing counterparts, the $6 \mathrm{~F}$-containing poly(ether imide)s
Table III. Tensile properties of poly(ether imide) films ${ }^{a}$

\begin{tabular}{|c|c|c|c|}
\hline \multirow{2}{*}{ Polymer code } & $\begin{array}{c}\text { Strength } \\
\text { at yield }\end{array}$ & $\begin{array}{l}\text { Strength } \\
\text { at break }\end{array}$ & $\begin{array}{c}\text { Elongation } \\
\text { at break }\end{array}$ \\
\hline & $\mathrm{MPa}$ & $\mathrm{MPa}$ & $\%$ \\
\hline $7_{\mathrm{a}}$ & - & 90 & 9 \\
\hline $7_{b}^{a}$ & - & 80 & 6 \\
\hline $7_{d}^{\circ}$ & - & 83 & 9 \\
\hline $7_{\mathrm{e}}^{a}$ & - & 79 & 6 \\
\hline $7_{\mathrm{f}}$ & 91 & 76 & 25 \\
\hline $7 g$ & 80 & 83 & 24 \\
\hline $7_{\mathrm{a}}^{\mathrm{g}}-\mathrm{F}$ & - & 103 & 11 \\
\hline $7 \mathrm{~b}-\mathrm{F}$ & - & 105 & 7 \\
\hline $7 d-F$ & - & 167 & 12 \\
\hline $7_{\mathrm{e}}-\mathrm{F}$ & - & 100 & 10 \\
\hline $7_{\mathrm{f}}-\mathrm{F}$ & 97 & 96 & 11 \\
\hline $7_{\mathrm{g}}-\mathrm{F}$ & 83 & 96 & 12 \\
\hline
\end{tabular}

a The films of $7_{c}$ and $7_{c}-F$ were too brittle to test.

Table IV. Thermal behavior data of poly(ether imide)s

\begin{tabular}{|c|c|c|c|c|}
\hline \multirow{2}{*}{$\begin{array}{l}\text { Polymer } \\
\text { code }\end{array}$} & \multirow{2}{*}{$\frac{T_{\mathrm{g}}{ }^{\mathrm{a}}}{{ }^{\circ} \mathrm{C}}$} & \multicolumn{2}{|c|}{$\begin{array}{l}\text { Decomposition } \\
\text { temperature }{ }^{\mathrm{b}} /{ }^{\circ} \mathrm{C}\end{array}$} & \multirow{2}{*}{$\begin{array}{c}\begin{array}{c}\text { Char } \\
\text { yield }^{\mathrm{c}}\end{array} \\
\%\end{array}$} \\
\hline & & In $\mathrm{N}_{2}$ & In air & \\
\hline $7_{\mathrm{a}}$ & 217 & 522 & 520 & 58.0 \\
\hline $7_{b}$ & 212 & 505 & 501 & 54.5 \\
\hline $7_{\mathrm{c}}$ & 243 & 522 & 521 & 62.7 \\
\hline $7_{d}$ & 211 & 512 & 517 & 59.0 \\
\hline $7_{\mathrm{e}}$ & 210 & 527 & 527 & 52.6 \\
\hline $7_{\mathrm{f}}$ & 204 & 519 & 524 & 54.1 \\
\hline $7_{\mathrm{g}}$ & 214 & 526 & 529 & 56.4 \\
\hline $7_{\mathrm{a}}-\mathrm{F}$ & 250 & 525 & 515 & 54.2 \\
\hline $7_{b}-F$ & 239 & 512 & 512 & 51.9 \\
\hline $7_{c}-F$ & 259 & 536 & 529 & 58.3 \\
\hline $7_{d}-F$ & 236 & 516 & 512 & 56.9 \\
\hline $7_{\mathrm{e}}-\mathrm{F}$ & 236 & 521 & 516 & 51.7 \\
\hline $7_{\mathrm{f}}-\mathrm{F}$ & 220 & 527 & 522 & 56.3 \\
\hline $7_{g}-F$ & 228 & 526 & 511 & 56.5 \\
\hline
\end{tabular}

${ }^{a}$ Midpoint of baseline shift in the second heating DSC trace, with a heating rate of $20^{\circ} \mathrm{C} \mathrm{min}^{-1}$ in nitrogen. ${ }^{b}$ Tempertures at which $10 \%$ weight loss were recorded by $\mathrm{TG}$ at a heating rate of $20^{\circ} \mathrm{C} \mathrm{min}^{-1}$. ${ }^{\mathrm{c}}$ Residual weight $\%$ at $800^{\circ} \mathrm{C}$ in nitrogen.

revealed an increased solubility. For example, most of polymers $7_{d-g}-$ F were also soluble in DMF and DMSO and even in less polar solvents like tetrahydrofuran (THF). It thus appears that the presence of the bulky flexible $-\mathrm{C}\left(\mathrm{CF}_{3}\right)_{2}-$ groups induces loose chain packing and, consequently, the solvent molecules can penetrate easily to solubilize the polymer chains.

The crystallinity of the poly(ether imide)s was examined by wide-angle X-ray diffraction. All the polymers, even those obtained from $p$-phenylenediamine and benzidine, showed amorphous patterns. The amorphous nature of these polymers can be mainly explained by the presence of flexible ether and isopropylidene or $6 \mathrm{~F}$ linkages in the polymer backbone. Except for the benzidine-derived poly(ether imide)s $\mathbf{7}_{\mathrm{c}}$ and $\mathbf{7}_{\mathrm{c}}-\mathbf{F}$, all the poly(ether imide)s could be processed into flexible and tough films. The tensile properties of these flexible films are given in Table III. The films of nonfluorine-containing polymers $7_{\mathrm{a}-\mathrm{g}}$ had a tensile strength of $76-90 \mathrm{MPa}$ and an elongation at break of $6-25 \%$. Polymers $7_{\mathrm{f}}$ and $7_{\mathrm{g}}$, which were derived from the bisphenol A bis(ether anhydride) with 1,4-bis(4-aminophenoxy) benzene $\left(\mathbf{5}_{\mathrm{f}}\right)$ 


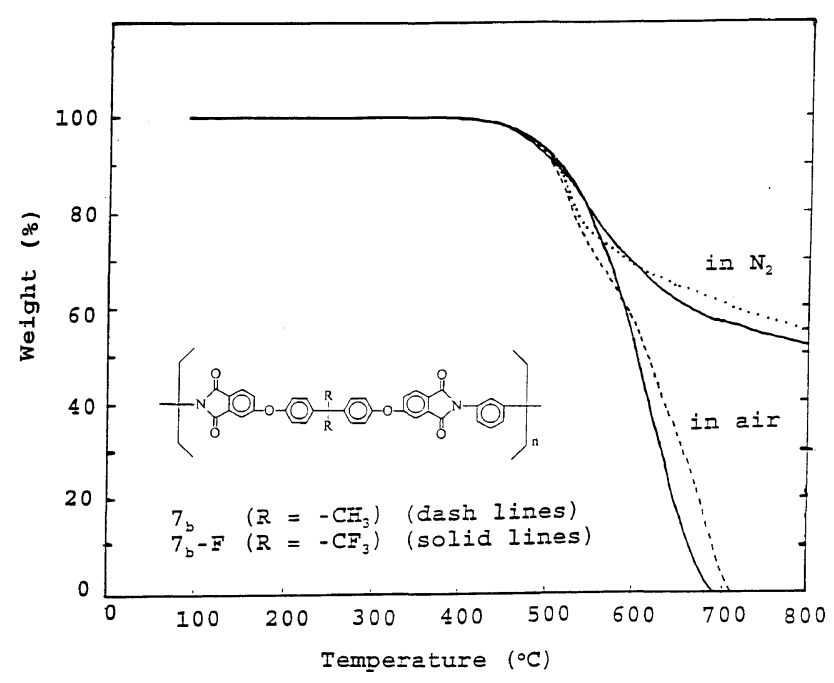

Figure 1. TG thermograms of poly(ether imide)s $7_{b}$ and $7_{b}-F$.

and 4,4'-bis(4-aminophenoxy)biphenyl $\left(5_{g}\right)$, respectively, behaved as a ductile material; they necked during testing and had a moderate elongation at break. The films of $6 \mathrm{~F}$-containing polymers $\mathbf{7}_{\mathbf{a}-\mathbf{g}}-\mathbf{F}$ exhibited a higher strength compared to those of nonfluoro polymers. They had tensile strengths in the range of $96-167 \mathrm{MPa}$ and elongations at break between $7-12 \%$. The poly(ether imide)s $\mathbf{7}_{\mathrm{f}}-\mathbf{F}$ and $\mathbf{7}_{\mathrm{g}}-\mathbf{F}$ obtained from diamines $\mathbf{5}_{\mathrm{f}}$ and $\mathbf{5}_{\mathrm{g}}$ also necked under tension; however, they showed a lower elongation at break than the corresponding nonfluoro polymers.

The thermal properties of the obtained poly(ether imide)s were investigated by differential scanning calorimetry (DSC) and dynamic TG. The results are summarized in Table IV. All the polymers were rapidly cooled from elevated temperatures at approximately $400^{\circ} \mathrm{C}$ to room temperature to form predominantly amorphous samples, and thus, distinct glass transitions could be observed on the subsequent heating DSC traces. The 7 series and 7-F series poly(ether imide)s exhibited $T_{\mathrm{g}} \mathrm{s}$ in linkages into the polymer chain resulted in a decrease in $T_{\mathrm{g}}$. Poly(ether imide)s $7_{\mathrm{a}-\mathrm{g}} \mathrm{-F}$ revealed higher $T_{\mathrm{g}} \mathrm{s}$ than the corresponding nonfluorinated $7_{\mathrm{a}-\mathrm{g}}$ by about 14 $23^{\circ} \mathrm{C}$, which may be due to the bulky structure of the $6 \mathrm{~F}$ group which retards the segmental mobility and hence leads to a higher $T_{\mathrm{g}}$. For example, the $6 \mathrm{~F}$-containing poly(ether imide) $7_{\mathrm{b}}-\mathrm{F}\left(T_{\mathrm{g}}=239^{\circ} \mathrm{C}\right)$ showed higher $T_{\mathrm{g}}$ by $17^{\circ} \mathrm{C}$ than the corresponding $7_{\mathrm{b}}\left(T_{\mathrm{g}}=212^{\circ} \mathrm{C}\right)$, a poly(ether imide) with the same structure as Ultem ${ }^{\circledR} 1000$.

As a representative example, the TG thermograms of poly(ether imide)s $7_{b}$ and $7_{b}-\mathbf{F}$ are reproduced in Figure 1. All the other poly(ether imide)s showed similar patterns of degradation with no significant weight loss before $500^{\circ} \mathrm{C}$ in air or nitrogen, but with more than $50 \mathrm{wt} \%$ residue remaining when heated to $800^{\circ} \mathrm{C}$ in nitrogen. The data reported in Table IV show that the $10 \%$ weight loss temperatures of poly(ether imide)s $7_{\mathrm{a}-\mathrm{g}}-\mathrm{F}$ were recorded in the range of $512-536^{\circ} \mathrm{C}$ in nitrogen and $512-529^{\circ} \mathrm{C}$ in air, and those of poly(ether imide)s $7_{\mathrm{a}-\mathrm{g}}$ were recorded in the range of $505-527^{\circ} \mathrm{C}$ in nitrogen and $501-529^{\circ} \mathrm{C}$ in air. In nitrogen atmosphere, all the fluorine-containing poly(ether imide)s showed a slightly higher $10 \%$ weight loss temperature than their nonfluorine-containing counterparts, possibly due to the high $\mathrm{C}-\mathrm{F}$ and $\mathrm{C}-\mathrm{CF}_{3}$ bond strengths. However, in air atmosphere, most of the isopropylidene-containing poly(ether imide)s showed a slightly higher value compared to their respective $6 \mathrm{~F}$-based counterparts. This may be explained by the fact that the polymers with aliphatic segments gain weight as they are oxidized, then rapidly lose weight as they degrade. Furthermore, it can also be noticed that there is a large window between the $T_{\mathrm{g}}$ and the decomposition temperature, which could be advantageous in the processing of these polymers.

\section{CONCLUSIONS}

Two series of poly(ether imide)s have been synthesized from the bis(ether anhydride)s containing the isopropylidene or hexafluoroisopropylidene group with aromatic diamines via a conventional two-step polymerization. Most of the poly(ether imide)s afforded flexible and tough films, even though some of them had low inherent viscosities. The obtained fluorine and nonfluorine-containing poly(ether imide)s had $T_{\mathrm{g}}$ values higher than $200^{\circ} \mathrm{C}$ and were thermally stable, with $10 \%$ weight loss temperatures being recorded above $500^{\circ} \mathrm{C}$. The fluoro poly(ether imide)s showed a higher $T_{\mathrm{g}}$ and an increased solubility compared to the corresponding nonfluoro polymers.

\section{REFERENCES}

1. D. Wilson, H. D. Stenzenberger, and P. M. Hergenrother, Ed., "Polyimides," Chapman and Hall, New York, N.Y., 1990.

2. M. K. Ghosh and K. L. Mittal, Ed., "Polyimides: Fundamentals and Applications," Marcel Dekker, New York, N.Y., 1996.

3. S. Matsuo and K. Mitsuhashi, J. Polym. Sci., Part A, Polym. Chem., 32, 1969 (1994).

4. G. C. Eastmond and J. Paprotny, Macromolecules, 28, 2140 (1995).

5. G. C. Eastmond, J. Paprotny, and R. S. Irwin, Macromolecules, 29, 1382 (1996).

6. S. Tamai, A. Yamaguchi, and M. Ohta, Polymer, 37, 3683 (1996).

7. N. Avella, G. Maglio, R. Palumbo, and M. C. Vignola, Polymer, 37, 4615 (1996).

8. S.-H. Hsiao, C.-P. Yang, and K.-Y. Chu, Macromolecules, 30, 165 (1997).

9. R. J. Jones and M. K. O'Rell (TRW Inc.), U. S. Patent 4,196,277 (1980) [Chem. Abstr., 93, 221295x (1980)].

10. Y. S. Negi, Y. Suzuki, I. Kawamura, Y. Takahashi, M. Ijima, M. Kakimoto, and Y. Imai, J. Polym. Sci., Part A, Polym. Chem., 30, 2281 (1992).

11. M. Bruma, B. Schulz, and F. W. Mercer, Polymer, 35, 4209 (1994).

12. M. Bruma, F. W. Mercer, J. Fitch, and P. Cassidy, J. Appl. Polym. Sci., 56, 527 (1995).

13. M. Bruma, I. Sava, F. W. Mercer, I. Negulescu, W. Daly, J. Fitch, and P. Cassidy, High Perform. Polym., 7, 411 (1995).

14. D. M. Stoakley, A. K. St. Clair, and C. I. Croall, J. Appl. Polym. Sci., 51, 1479 (1994).

15. G. S. Matvelashvili, A. L. Rusanov, V. M. Vlasov, G. V. Kazakova, and O. Yu. Rogozhnikova, Vysokomol. Soedin., Ser. A, Ser. B, 37, 1941 (1995).

16. S.-H. Hsiao, C.-P. Yang, and C.-K. Lin, J. Polym. Res., 2, 1 (1995). 